\title{
Oportunidades y Riesgos en la decisión del caso BG Group vs. Argentina ${ }^{\star}$
}

\author{
Luis Miguel Velarde Saffer ${ }^{* *}$ y Jonathan W. Lim ${ }^{* * *}$
}

SUMARIO: 1. Jurisdicción vs. Admisibilidad: Consentimiento y la "Zona Gris". 2. La Importancia del Lugar del Arbitraje. 3. ¿Debe el arbitraje de inversión tener un tratamiento diferente del arbitraje comercial? De ser el caso ¿qué tan diferente? 4. ¿Un arbitraje bajo el Convenio CIADI sería diferente?

\section{Jurisdicción vs. Admisibilidad: Consentimiento y la "Zona Gris"}

El asunto central en la apelación consiste en si, en el contexto de un arbitraje de inversión, las cortes norteamericanas deben otorgar deferencia a las decisiones arbitrales sobre el cumplimiento de pre-condiciones al arbitraje, o si por el contrario pueden decidir de manera independiente y de novo tales asuntos. En otras palabras, el asunto no se refiere únicamente a si un inversionista puede válidamente iniciar un arbitraje sin haber antes litigado ante las cortes locales, sino además si son los árbitros o las cortes quienes tienen la decisión final sobre el cumplimiento de las pre-condiciones al arbitraje. Esta es una cuestión más general que concierne a la distribución de responsabilidades entre las cortes nacionales y los árbitros.

\footnotetext{
* Traducción al español del artículo "Opportunities and Risks in the Upcoming BG Group v. Argentina Decision", publicado en inglés en Transnational Dispute Management 3 (2014). Traducción efectuada por Andrea Zegarra Ballón, abogada por la Universidad de Lima y Master por el IE Business School. El presente artículo, publicado a inicios del 2014, propuso recomendaciones para la solución del caso BG Group y presentó, con miras al futuro, un marco analítico para decidir casos límite (denominados “Zona Gris") entre jurisdicción y admisibilidad. Habiéndose publicado, el 5 de marzo de 2014, el fallo de la Corte Suprema de los Estados Unidos en el caso BG Group, el presente artículo (publicado antes de la emisión de dicho fallo) permite analizar el proceder de la Corte y constatar si el panorama para futuros casos en la Zona Gris ha sido aclarado.

** Asociado en Dechert París LLP. Harvard Law School, LL.M, Abogado por la Pontificia Universidad Católica del Perú. Árbitro de la Cámara de Comercio de Lima, Árbitro y dell Centro de Análisis y Resolución de Conflictos de la Pontificia Universidad Católica del Perú.

*** Asociado en Wilmer Cutler Pickering Hale \& Dorr LLP. LL.B por la Universidad Nacional de Singapur y LLM por la Escuela de Derecho de Harvard, y es un receptor de varios premios académicos de ambas instituciones. Está capacitado para ejercer en Nueva York y Singapur.
} 
La respuesta a esta cuestión tiene un impacto fundamental en si las partes obtienen el proceso que acordaron y, por consiguiente, si el proceso de arbitraje de inversión será visto como válido y eficaz ${ }^{1}$. El desafío consiste en identificar correctamente si la cuestión plantea un asunto referido a la jurisdicción, que las cortes nacionales pueden revisar de novo, o si se refiere a un asunto de mera admisibilidad, donde la decisión de los árbitros debe ser tratada con deferencia. ${ }^{2}$ A pesar de que hay casos claros, la mayoría de los comentaristas concuerda en que existe una Zona Gris de casos difíciles, es decir, un espectro de casos complejos que se resisten a una sencilla clasificación. BG Group es interesante precisamente porque cae dentro de la mencionada Zona Gris.

De acuerdo con la ley de arbitraje de los Estados Unidos de Norteaméri$\mathrm{ca}$, la distribución de los roles entre cortes y árbitros se realiza utilizando el término (erróneo) "arbitrabilidad"3. Las cortes americanas se preguntarán, respecto a la cuestión de la arbitrabilidad, si las partes quisieron someter dichas cuestiones a los árbitros o a las cortes. Para responder esto, la línea de casos Howsam distingue entre asuntos de arbitrabilidad sustantiva (jurisdicción) y asuntos de arbitrabilidad procesal (admisibilidad): las cortes pueden revisar de novo cuestiones relacionadas a la primera pero deben dar deferencia a las decisiones de los árbitros respecto de las últimas. Bajo esta dicotomía en la ley estadounidense, la Corte Suprema ha establecido que "las pre-condiciones a la obligación de arbitrar" son "procesales" y en consecuencia a ser decididas por los arbitros ${ }^{4}$. A pesar de esta categorización aparentemente sencilla, los argumentos intercambiados en el caso $B G$ Group ponen en duda cualquier suposición general de que las "pre-condiciones" deben siempre ser tratadas por las Cortes como de naturaleza procesal.

1. Como uno de los comentaristas explica con precisión: "las decisiones de un tribunal que no respetan su jurisdicción podrán ser anuladas por el órgano o autoridad de control. Sin embargo, si las partes se han sometido a la jurisdicción de un tribunal, sus determinaciones sobre la admisibilidad de la pretensión deben ser finales. Clasificar erróneamente cuestiones de admisibilidad como de jurisdicción puede por tanto dar lugar a una extensión injustificada de las causales para impugnar laudos, y frustrar las expectativas de las partes de que su disputa será decidida por el tribunal neutral elegido". Véase J. PAULSSON, "Jurisdiction and Admissibility", en Gerald Aksen y otros (eds), Global Reflections on International Law, Commerce and Dispute Resolution: Liber Amicorum en Honor de Robert Briner, Publicaciones ICC, Publicación 693, p. 601.

2. Una forma de hacer la distinción conceptual es: los cuestionamientos a la jurisdicción tienen como objetivo cuestionar la facultad de los árbitros para decidir la disputa, mientras que los cuestionamientos de admisibilidad se refieren a la posibilidad de plantear la pretensión, sin importar quién emitirá el laudo o fallo.

3. Este es un uso confuso en los Estados Unidos - relativo a cuestiones que deban resolverse por jueces o árbitros -que no está en línea con el significado común internacional del término "arbitrabilidad", que generalmente se refiere a la posibilidad de someter a abitraje la materia controvertida, o en otras palabras, a los límites establecidos por las políticas públicas respecto de los tipos de asuntos que podrán ser sometidos a arbitraje. La Ley Modelo de la CNUDMI refleja este concepto de arbitrabilidad. Bajo este uso común, por ejemplo, se podría decir que asuntos de naturaleza penal no son arbitrables en la mayoría de países. John Wiley \& Sons, Inc c. Livingston, 376 U.S. 543 (1964). 
Las disposiciones relevantes del TBI Gran Bretaña - Argentina son los artículos 8(1) y 8(2) de la Cláusula de Solución de Controversias, que establecen lo siguiente ${ }^{5}$ :

1. Disputas respecto a una inversión que surgen dentro de los términos de este Acuerdo entre un inversionista de una Parte Contratante y la otra Parte Contratante, que no han sido resueltas en forma amistosa deberán ser sometidas, a pedido de una de las partes, a la decisión del tribunal competente de la Parte Contratante en cuyo territorio la inversión fue realizada.

2. Las mencionadas disputas deberán ser sometidas a arbitraje internacional en los siguientes casos:

a) si una de las partes lo solicita, en algunas de las siguientes circunstancias:

i) Cuando, luego de transcurrido un período de 18 meses desde el momento en que la disputa fue sometida al tribunal competente de la Parte Contratante en cuyo territorio la inversión fue realizada, dicho tribunal no haya emitido una decisión final;

ii) Cuando la decisión final del tribunal antes mencionado haya sido emitida pero las partes aún continúan en disputa;

b) cuando la Parte Contratante y el inversionista de la otra Parte Contratante así lo han acordado.

En un inteligente replanteamiento de las cuestiones sometidas a la Suprema Corte ${ }^{6}$, Argentina ha calificado la exigencia de pasar por las cortes locales como una condición de su consentimiento al arbitraje. Aquella consistiría en una condición para la existencia misma de un acuerdo de arbitraje, en lugar de una condición previa a la ejecución de la obligación de arbitrar (que supone la existencia de un acuerdo válido de arbitraje). Esto altera los términos del debate, toda vez que la validez o existencia de un acuerdo de arbitraje son considerados, bajo la ley existente, como cuestiones de arbitrabilidad sustantiva. La caracterización efectuada por Argentina exige entonces que

5. Infra 2.

6. Una objeción similar fue planteada por el demandado en el caso John Wiley. Véase J.WILEY, infra 7, p. 918. 
la Corte se pronuncie sobre si existe consentimiento al arbitraje de inversión sólo cuando las condiciones que requieren previo litigio ante el fuero judicial local se cumplen, o si el consentimiento de los Estados se produce una vez que se celebra el Tratado.

Sin negar la lógica interna al argumento de Argentina, hay quizás una circularidad peligrosa aquí. Si la Corte Suprema acepta la argumentación de Argentina, abriría la puerta para que los demandados formulen objeciones basadas en la ausencia de consentimiento cada vez que una condición procesal no se cumpla, sin importar lo trivial que aquella pueda ser. De aquí la aparente obsesión de la Corte Suprema en los alegatos orales respecto de cómo se analizaría un requisito de que algo "se presente en papel azul", y si podría sustentarse una objeción basada en la ausencia de consentimiento si los documentos se presentaran en papel blanco ${ }^{7}$. Aunque obviamente una reductio ad absurdum, dicho cuestionamiento demuestra que la posición de Argentina amenaza con anular la línea divisoria existente en el Derecho americano (para analizar la naturaleza de las pre-condiciones) sin proponer ninguna mejor alternativa.

En última instancia, la posición de Argentina simplemente omite la pregunta de cómo se deben distribuir las responsabilidades entre los tribunales y árbitros. Si la propuesta de Argentina es aceptada, en cada caso donde una parte alegue la falta de consentimiento, las cortes revisarán la objeción de novo y decidirán si el consentimiento fue otorgado o no. Por ejemplo, si la Corte Suprema decide que existió consentimiento al arbitraje, las pre-condiciones constituirían cuestiones de mera arbitrabilidad procesal y la decisión de los árbitros deberá ser tratada con deferencia. Por otro lado, si la Corte decide que no existió consentimiento, los árbitros se habrían equivocado al declararse competentes y la Corte debería anular su decisión. En resumen, la Corte puede alcanzar cualquier resultado mediante la revisión de novo del asunto. Sin embargo, esto ya presume la respuesta a la pregunta planteada a la Corte en primer lugar, es decir, si se debe otorgar deferencia a la decisión de los árbitros. La propuesta de Argentina entonces inclina la balanza a favor de la revisión de novo.

Lo que este debate ilustra es lo difícil que puede resultar distinguir entre jurisdicción y admisibilidad en la Zona Gris. A diferencia de asuntos que claramente se refieren a admisibilidad por un lado (tales como prescripción

7. Véase la transcripción de las alegaciones orales, BG Group PLC c. Republic of Argentina (Corte Suprema de los Estados Unidos), 2 de Diciembre de 2013, pp. 21, 31, 51. 
y estoppel), y aquellos referidos claramente a jurisdicción (tales como la validez del acuerdo arbitral), los casos en la Zona Gris se resisten a una simple clasificación. En estos casos, el enfoque estadounidense de centrarse en quién quisieron las partes que tenga la última palabra en cuestiones particulares de "arbitrabilidad" resulta irreal, ya que las partes normalmente no consideran esta cuestión. En ausencia de un acuerdo expreso de las partes, entonces, la línea divisoria entre jurisdicción y admisibilidad descansa sobre la base incierta de las intenciones presuntas de las partes, proporcionando así a los tribunales un margen demasiado amplio para decidir una cuestión de novo, y potencialmente frustrando el mecanismo de solución de controversias elegido por las partes.

Debe ser evidente que la exigencia de litigación no vinculante en las cortes del Estado anfitrión es un caso de Zona Gris dada la gran cantidad de memoriales amicus curiae remitidos en respaldo tanto de $B G$ Group como de Argentina. El artículo 8 del TBI Argentina - Gran Bretaña es inusual al requerir el inicio de acciones en las cortes locales, y al mismo tiempo establecer que la decisión de los tribunales locales no resultan definitivas y que el inversionista puede recurrir al arbitraje si no está satisfecho con la decisión judicial o han transcurrido más de 18 meses. Debido a la disposición que permite el arbitraje después de un lapso de tiempo, dicha exigencia no califica como una de "agotamiento de los remedios internos", que es generalmente considerada como de carácter jurisdiccional ${ }^{8}$. Por otro lado, a diferencia de las cláusulas de resolución de conflictos escalonadas que exigen mediación o intentos de conciliación previos, que han sido consideradas en la legislación estadounidense como cuestiones de admisibilidad, el artículo 8 requiere un recurso previo a los tribunales locales de Argentina, es decir, a un foro muy diferente con poderes adjudicativos.

La literatura y jurisprudencia postulan varios posibles tests o factores para navegar por la Zona Gris, pero desafortunadamente ellos no aclaran el panorama en el caso BG Group. En John Wiley, la Corte tomó en consideración cuán estre-

8. Véase PAulsson, infra 4, p. 616. Véase también Maffezini c. Spain, Decisión de Jurisdicción, 25 de enero de 2000, párr. 38 y siguientes, disponible aquí: http://www.italaw.com/sites/default/files/case-documents/ita0480.pdf; Siemens c. Argentina, Decisión de Jurisdicción, 3 de agosto de 2004, párr. 82 y siguientes, disponible aquí: http://www.italaw.com/sites/default/files/case-documents/ita0789.pdf. En efecto, el artículo 26 de la Convención de Washington expresamente prevé, en arbitrajes CIADI, los Estados podrán requerir el agotamiento de los remedios internos como "una condición para su consentimiento al arbitraje", disponible aquí: https://icsid.worldbank.org/ICSID/StaticFiles/basicdoc/CRR_English-final.pdf. 
chamente ligada estaba la satisfacción de las pre-condiciones al fondo de la controversia". El Tribunal sostuvo que "sería una regla curiosa aquella que exija que cuestiones entrelazadas de "sustancia" y "procedimiento"derivadas de una misma disputa y que plantean interrogantes sobre los mismos hechos tuvieran que ser repartidas entre dos foros diferentes, uno decidiendo después del otro". Aplicando esto en el caso BG Group, los mismos hechos que dieron lugar a la controversia (las medidas de emergencia adoptadas por el Gobierno argentino) son prácticamente inseparables de los hechos en los que el tribunal arbitral fundamentó su decisión de excusar a BG Group del cumplimiento del requisito de litigación local. Esto por lo tanto argumenta a favor de considerar la satisfacción de la pre-condición como una cuestión de admisibilidad.

Sin embargo, otro test apunta en la dirección contraria. Jan PAULSSON ha sugerido que "la relevancia de la objeción para la naturaleza del foro" es una consideración primordial para determinar si una pre-condición va hacia el lado de jurisdicción o de admisibilidad ${ }^{10}$. En otras palabras, la pregunta es "si el éxito de la objeción necesariamente niega el consentimiento al foro" (énfasis añadido) ${ }^{11}$. Debido a que la pre-condición en el caso BG Group es recurrir a las cortes argentinas, la objeción de Argentina en este caso involucraría el "consentimiento al foro". Bajo este test, en consecuencia, podría argumentarse que la objeción tiene carácter jurisdiccional. No obstante, el resultado opuesto puede también ser argumentado bajo el test de Paulsson. Debido a que el artículo 8 faculta al inversor a presentar una demanda arbitral después de cierto período de tiempo, la objeción de Argentina no necesariamente niega consentimiento al fuero arbitral. Si este es el caso, entonces, puede argumentarse que la objeción involucra solamente una cuestión de admisibilidad.

Ante estas dificultades, los autores hacen dos contribuciones para el análisis y posible solución de los casos ubicados en la Zona Gris y, en particular, del caso BG Group. Sugerimos que este último debería ser resuelto a favor de otorgar deferencia a la decisión de los árbitros respecto de la pre-condición, sobre la base de: i) la forma piramidal de la cláusula escalonada de solución de controversias, con todos los caminos llegando al arbitraje; y alternativamente, ii) la adopción de una presunción de sentido común de que las partes han consentido incondicionalmente al arbitraje.

9. J. WILEY, infra 7, p. 556.

10. PAULSSON, infra 4, p. 616.

11. Ibídem. 
Primero, se sugiere que una posible solución del caso BG Group puede encontrarse en la particular forma y estructura de la cláusula escalonada de solución de controversias del TBI Argentina - Gran Bretaña. Se debe distinguir entre una pre-condición que requiere el recurso previo a un foro adjudicativo capaz de emitir una decisión final y vinculante, y una pre-condición que requiere recurso a un foro no vinculante o no adjudicativo. En el último, como es el caso de BG Group, debido a que todos los caminos conducen al arbitraje se puede argumentar que existe consentimiento para que sea un tribunal arbitral quien decida la disputa. El requisito del recurso previo a un foro alternativo entonces se asimila a un período de espera. Por el contrario, en el primer caso, la disputa es capaz de ser resuelta concluyente y definitivamente mediante la adjudicación en el primer foro, y en consecuencia el consentimiento al foro arbitral puede ser considerado como condicional respecto del primer recurso. Por ejemplo, una cláusula similar al artículo 8 del TBI Argentina - Gran Bretaña, pero que no contemple la posibilidad de apelar la decisión de las cortes locales (es decir, sólo podrá llegarse a arbitraje si no se emite una decisión en 18 meses), caería dentro de la categoría jurisdiccional. Bajo este análisis, el punto clave para decidir si el requisito del recurso previo es una pre-condición a la existencia del acuerdo de arbitraje es la forma de la cláusula: si ha sido diseñada como una "pirámide", donde todos los caminos llevan al arbitraje ubicado en el cima, o como un "tenedor"12, donde las partes pueden ser sometidas a más de un foro que podrá emitir una decisión definitiva y vinculante sobre el fondo de la controversia.

En segundo lugar y alternativamente, una solución más amplia del caso $B G$ Group se puede alcanzar mediante la adopción de una regla general de acuerdo con la cual, ante la ausencia de una estipulación expresa que condicioione el consentimiento, se presuma que las partes han consentido incondicionalmente al arbitraje. Existen fuertes razones a favor de esta regla de sentido común, particularmente en el caso del arbitraje de inversión. Cuando los Estados entran en un Tratado que contempla un arbitraje, es razonable creer que aquellos quisieron que las disputas fueran resueltas por un tribunal arbitral con experiencia en derecho internacional. Como la determinación de la naturaleza y el cumplimiento de las pre-condiciones para el arbitraje generalmente involucra la interpretación de tratados conforme al derecho internacional, y el consentimiento de un Estado Soberano es un

12. No confundir con las cláusulas de fork in the road, que no se refieren a las pre-condiciones al arbitraje. 
asunto de derecho público internacional, tiene sentido presumir que un tribunal arbitral con conocimiento en derecho internacional es el órgano indicado para resolver este tipo de disputas. Esta presunción es también consistente con la Convención de Viena, que resulta aplicable a la cláusula arbitral contenida en el TBI Argentina - Gran Bretaña ${ }^{13}$. En línea con la interpretación textual de la Convención de Viena, que requiere adhesión estricta al texto del tratado sobre cualquier intención no expresada de las partes, la regla propuesta restringiría interpretaciones creativas de las cortes o los árbitros en casos complejos.

Esta regla traería muchos beneficios al sistema de arbitraje de inversión como un todo. Si la Corte Suprema confirmase la decisión de la Corte de Circuito de D.C. de revisar de novo el laudo arbitral, esto incentivaría a los Estados demandados a abusar del sistema presentando objeciones amorfas de ausencia de consentimiento. Si las partes sólo pueden plantear tales objeciones cuando su consentimiento haya sido expresamente condicionado, se avanzaría en la creación de un proceso más eficiente "de una sola parada" para la solución de disputas de inversión. Dicha regla también proveería mayor certeza y predictibilidad. Adicionalmente, esta regla general también reduce el riesgo de error en las decisiones. Debido a que la revisión de decisiones arbitrales en disputas de inversión puede llegar a las cortes nacionales mucho después de la celebración del Tratado en cuestión, muy poca información podría estar disponible para que las cortes puedan interpretar el Tratado y determinar los hechos de la disputa. En cambio, el tribunal arbitral está constituido mucho más cerca en el tiempo al surgimiento de la disputa, y además tendrá el beneficio de haber apreciado directamente la evidencia del caso. Finalmente, esta regla general no sería costosa para los Estados, toda vez que ellos podrán negociar fácilmente e incluir el lenguaje relevante en sus tratados de inversión. En un análisis simple de costo-beneficio, en consecuencia, los autores favorecen y abogan por establecer una presunción de consentimiento incondicional de las partes al arbitraje.

13. Convención de Viena sobre el Derecho de los Tratados, 23 de Mayo de 1969, disponible aquí: https://treaties.un. org/doc/Publication/UNTS/Volume\%201155/volume-1155-I-18232-English.pdf (en adelante, la "Convención de Viena"). El artículo 31(1) de la Convención de Viena otorga primordial importancia al "sentido ordinario" de los "términos del tratado", y permite una referencia muy limitada a materiales ajenos al mismo. 


\section{La importancia del lugar del arbitraje}

Las complejidades envueltas en distinguir entre admisibilidad y jurisdicción en casos difíciles solo sirven para reforzar la importancia de elegir cuidadosamente la sede del arbitraje. En casos difíciles que involucran, como en el presente caso, tener que litigar localmente por un período de tiempo limitado, las cortes nacionales pueden diferir marcadamente en su caracterización del requisito y el grado de revisión judicial debido a la inherente complejidad de la tarea, los diferentes elementos fácticos y los términos de las leyes que regulan el vacatur de los laudos.

Es más, las cortes pueden diferir incluso en casos menos complejos. En el caso International Research Corp PLS c. Lufthansa, la Corte de Apelaciones de Singapur analizó el cumplimiento de ciertos procedimientos de negociación que requerían ser agotados antes del inicio de un arbitraje. El tribunal arbitral había concluido que dichos procedimientos eran muy inciertos para que su cumplimiento fuese exigido. El demandado intentó anular el laudo ante la Alta Corte de Singapur pero fracasó ${ }^{14}$. La Alta Corte consideró que, a pesar de que los compromisos pre-arbitraje eran exigibles, ellos fueron cumplidos en el caso. En apelación, no obstante, la Corte de Apelaciones revocó la decisión ${ }^{15}$. A pesar de los diferentes resultados, ambas cortes dieron por sentado que el requisito de sostener negociaciones preliminares involucraba la jurisdicción del tribunal arbitral y, por ende, que la corte podía decidir de novo. Bajo John WiLEY, este mismo requisito en los Estados Unidos sería caracterizado como una cuestión de "arbitrabilidad procesal", y por ende decidido otorgando deferencia a los árbitros ${ }^{16}$.

Un análisis más profundo de la legislación y de la jurisprudencia de las jurisdicciones relevantes, teniendo en mente sus raíces de derecho civil o derecho anglosajón, requiere ser realizado para determinar cómo aquellas

14. International Research Corp PLC c. Lufthansa System Asia Pacific Pte Ltd y otro (2012), disponible aquí: http:// www.singaporelaw.sg/sglaw/laws-of-singapore/case-law/free-law/high-court-judgments/15051-internationalresearch-corp-plc-v-lufthansa-systems-asia-pacific-pte-ltd-and-another-2012-sghc-226.

15. International Research Corp PLC c. Lufthansa System Asia Pacific Pte Ltd y otro (2013) SGCA 55, disponible aquí: http://www.singaporelaw.sg/sglaw/images/ArbitrationCases/2014\%201\%20SLR\%20130.pdf.

16. Para otros ejemplos de los diferentes tratamientos dados por cortes nacionales a asuntos similares, considerar la decisión emitida por las cortes británicas en Wah (aka Tang) c. Grant Thornton International (GTILL) Ltd. (2012), EWHC 3198 (Ch), disponible aquí: http://www.bailii.org/ew/cases/EWHC/Ch/2012/3198.html, donde una cláusula similar (como Lufthansa) fue considerada inexigible. 
analizan el asunto. Confianza en la buena reputación del país como sede del arbitraje puede no ser suficiente. De hecho, jurisdicciones pro arbitraje, como Suiza, pueden ser fuente de decisiones que contrapuestas al consenso internacional. En Vekoma B.V. c. Maran Coal Corp., luego de concluir que un plazo de 30 días para presentar una demanda arbitral constituía un requisito de jurisdicción, el Tribunal Federal Suizo realizó un análisis de novo y anuló el laudo ${ }^{17}$. En los Estados Unidos, bajo Howsam, se habría respetado la decisión de los árbitros.

Inclusive si las cortes coinciden en la caracterización de una pre-condición, el estándar de revisión que ellos aplican puede ser diferente. En Canada c. S.D. Myers $^{18}$, la Corte Federal de Canadá tuvo que determinar qué estándar de revisión aplicar a un asunto de jurisdicción. Específicamente, Canadá negó que S.D. Myers calificase como un "inversor" o que 'una inversión hubiese sido realizada por un inversor' bajo el tratado aplicable. La corte falló que, mientras un estándar de corrección (equivalente a la revisión de novo estadounidense) aplicaba a cuestiones de derecho, un estándar de razonabilidad aplicaba a cuestiones que involucraban derecho y hechos ${ }^{19}$. Este enfoque difiere de aquel utilizado por las cortes estadounidenses, las que solo aplican un estándar de novo para la revisión de asuntos jurisdiccionales, sin hacer distinciones entre cuestiones de derecho y hechos.

\section{3. ¿Debe el arbitraje de inversión tener un tratamiento diferente del arbitraje comercial? De ser el caso ¿qué tan diferente?}

Dado que $B G$ Group es el primer arbitraje de inversión que llegó a la Corte Suprema, surge la duda sobre si la Corte Suprema debe simplemente extender Howsam sin limitaciones, o si debe modificar Howsam para tomar en consideración que este es un arbitraje bajo un tratado de inversión. Al respecto, el amicus curiae de los Estados Unidos se enfocó en hacer una distinción entre la revisión de los laudos arbitrales de inversión y la revisión de laudos arbitrales en el contexto de un arbitraje comercial privado. Estados Unidos argumentó que las presunciones locales, bajo First

17. Transport - en Handelsmaatschappij 'Vekoma'B.Y. c. Maran Coal Corporation, fallo del 17 de agosto 1995, Boletín ASA 1996, p. 673.

18. Canada c. S.D. Myers Inc. (2004) 3 F.C.R. 368, disponible aquí: http://reports.cmf-fja.gc.ca/eng/2004/2004fc38. html

19. Ibídem. 
Options y Howsam, no resultan aplicables a un laudo arbitral de inversión, sugiriendo que la Corte debía siempre "revisar independientemente las decisiones arbitrales sobre objeciones basadas en la ausencia de un acuerdo arbitral válido, y otorgar deferencia a otras decisiones". Bajo esta regla, el estándar de revisión se enfocaría en la "naturaleza de la objeción" antes que en el intento de la Corte de adivinar la intención de las partes.

Durante los alegatos orales ante la Corte Suprema, diversos Jueces otorgaron muy poca atención a esta línea de argumentación, al no estar convencidos de que existiera alguna razón para dejar de lado el enfoque existente bajo Howsam. El test estadounidense propuesto, en efecto, tiene varios defectos, entre los que se cuenta que la propuesta busca desplazar el test Howsam sin ofrecer ningún criterio útil para trazar la línea entre cuestiones evidentes de admisibilidad y de jurisdicción. De hecho, esta propuesta tiene el mismo problema de circularidad del argumento de la Argentina basado en la ausencia de consentimiento. Adicionalmente, aceptar la propuesta estadounidense de tener una regla absoluta de revisión de novo basada en la forma en que el demandado caracterice su objeción es altamente indeseable por diversas razones de política, incluyendo que podrá permitir que Estados demandados abusivos hagan aun más cuestionamientos obstructivos y dilatorios luego que el laudo arbitral se emita.

A pesar de que la propuesta estadounidense resulte poco convincente, aún vale la pena formular la pregunta: ¿existen diferencias relevantes entre un arbitraje de inversion basado en un tratado y un arbitraje comercial privado y, de ser así, aquellas justifican una aproximación diferente o modificada? Los autores postulan que existen diferencias relevantes, aunque ellas no necesariamente apuntan hacia la misma dirección que el amicus curiae estadounidense. A mayor abundamiento, inclusive si dichas diferencias no influyen en el resultado de este caso, se sugiere que la Corte Suprema debería cuidarse de emitir pronunciamientos generales en el caso BG Group que puedan restar importancia a tales diferencias en casos futuros.

Primero, en arbitrajes bajo tratados de inversión, el acuerdo arbitral y sus términos siempre se encuentran en tratados de inversión que son analizados bajo el derecho internacional y, en particular, la Convención de Viena. En consecuencia, en arbitrajes de inversión, los árbitros son u- 
sualmente elegidos por su experiencia particular en derecho de inversiones o derecho internacional, entre otras razones. En comparación con las cortes nacionales, los árbitros están normalmente mejor posicionados para decidir asuntos relativos a la naturaleza y cumplimiento de las precondiciones contenidas en el acuerdo arbitral. Por el contrario, el análisis de acuerdos arbitrales en arbitrajes comerciales privados esencialmente involucra la interpretación de contratos y la aplicación de principios contractuales bajo una ley nacional particular. Esta ley puede ser una ley extranjera, como la ley de Nueva York, tanto para las cortes como para los árbitros. Al lidiar con estos casos, los árbitros no necesariamente están mejor posicionados que las cortes para decidir cuestiones relativas a la naturaleza y cumplimiento de los términos del acuerdo arbitral. Asimismo, la Convención de Viena consagra una interpretación textualista de los tratados que difiere significativamente de la mayoría de reglas nacionales de interpretación contractual ${ }^{20}$. En un caso "Zona Gris", estas consideraciones pueden inclinar la balanza hacia el otorgamiento de deferencia a la decisión de los árbitros.

En segundo lugar, los tratados de inversión constituyen tipos especiales de acuerdos con características únicas que pueden influir en la óptima distribución de responsabilidades entre cortes y árbitros. Por ejemplo, los tratados de inversión son a menudo celebrados muchos años antes de una disputa ${ }^{21}$. Para la parte estatal, la prueba de su expresión de voluntad y su consentimiento al arbitraje será encontrada en el tratado mismo, el cual es considerado como una oferta unilateral para arbitrar ciertas disputas con cierta clase de personas. Es sólo cuando surge una controversia y un reclamo es presentado por un inversor que el acuerdo arbitral entre el Estado y el inversor se entiende celebrado. Bajo Howsam, las cortes americanas deben descifrar cuáles fueron las intenciones de las partes respecto a si son las cortes o los árbitros quienes tienen la responsabilidad primaria para decidir cuestiones vinculadas al consentimiento al arbitraje. Considerando

20. La jerarquía de fuentes consagrada en los artículos 31 al 33 de la Convención de Viena limita considerablemente la libertad para realizar una interpretación (del tratado) que no se base en la literalidad. Por el contrario, tanto las cortes nacionales como las estadounidenses han tendido a otorgar deferencia a interpretaciones subjetivas (fuera del texto) realizadas por organismos ejecutivos. Véase E. J. CRIDDLE, “The Vienna Convention on the Law of Treaties in U.S. Treaty Interpretation”, Virginia Journal of International Law, Vol. 44, No. 2, p. 435 (2004), disponible aquí: file://C:/Users/LVelardeSaffer/Downloads/SSRN-id1004197.pdf. Véase también la discusión en infra 16.

21. Este también puede ser el caso de los contratos de larga duración, que pueden requerir un análisis caso por caso a fin de decidir si el argumento del transcurso del tiempo también aplica. En relación con estos contratos, sin embargo, el contraste hecho por los autores entre arbitraje de inversión y el arbitraje comercial, por las demás razones presentadas en esta sección, aún se mantiene. 
que en un arbitraje inversor-estado éstos asuntos involucrarán la interpretación de obligaciones en tratados negociados y celebrados muchos años o inclusive décadas antes, sería razonable presumir que las partes quisieron que fueran los árbitros, más cercanos en el tiempo que las cortes de la sede del arbitraje, quienes decidan éstos asuntos ${ }^{22}$. Como se mencionó antes, que sean los árbitros (y no las cortes) quienes decidan tales asuntos implica un menor riesgo de error en la decisión. Por el contrario, el factor del transcurso del tiempo no es normalmente tan importante en los arbitrajes comerciales privados debido a que el acuerdo arbitral normalmente se celebra al mismo tiempo que el contrato que lo contiene. Adicionalmente, el plazo de prescripción bajo la ley nacional aplicable limita el espectro de tiempo que puede transcurrir.

Tercero, los tratados de inversión implican el consentimiento de un Estado para múltiples posibles arbitrajes antes que el consentimiento para un solo arbitraje, como es normalmente el caso de un arbitraje comercial privado. Considerando que la sede del arbitraje involucra normalmente un tercer Estado no relacionado con las partes del tratado, así como que muchos arbitrajes, involucrando múltiples sedes, pueden derivar de un único tratado de inversión, una regla que presuma -en un arbitraje de inversión- la intención de las partes de que sean los árbitros quienes decidan los asuntos de admisibilidad/competencia así como la interpretación de los términos del arbitraje parece razonable. Esto es especialmente así desde que el Tratado normalmente no hace ninguna referencia a las cortes de la sede del arbitraje. Como una cuestión de política, dejar decisiones a una multiplicidad de posibles cortes nacionales con ninguna conexión directa con la disputa, en oposición a los árbitros elegidos por las partes, es altamente indeseable toda vez que generaría incertidumbre e indeterminación, y comprometería la autonomía de las partes. Además, a diferencia de las cortes nacionales, quienes tienen sus propias preocupaciones de políticas públicas locales, los árbitros y expertos internacionales tienen mayores incentivos para generar consistencia en las decisiones respecto de tales asuntos. Estas consideraciones no surgen en el contexto de arbitrajes comerciales privados.

22. Mientras que la cercanía en el tiempo podría no afectar materialmente la interpretación de las cláusulas en el Tratado y la determinación de la voluntad de las partes, el factor tiempo es muy importante en relación con la determinación de las cuestiones fácticas, que pueden ser especialmente importantes al analizar el cumplimiento de precondiciones, o las justificaciones para su no cumplimiento. 
Finalmente, en los arbitrajes de inversión, el consentimiento a un arbitraje inversor-Estado es el quid-pro-quo para que se realice la inversión bajo el tratado. Bajo el derecho internacional tradicional, antes de la proliferación de los tratados de inversión, los inversores no tenían mecanismos para presentar reclamos directos contra el Estado receptor de la inversión; en su lugar, aquellos dependían de mecanismos usualmente poco eficaces como la protección diplomática. Pero todo esto cambió radicalmente algunas décadas atrás con la proliferación de los tratados bilaterales de inversión y los tratados de libre comercio, una de cuyas protecciones principales (para los inversores) la constituye el consentimiento de los Estados al arbitraje, mediante el cual renuncian a su inmunidad soberana. Este consentimiento al arbitraje, sin duda, fue una de las condiciones críticas para el desarrollo de la inversión extranjera directa. Por el contrario, la importancia colocada en el acuerdo de arbitraje podría no ser tan evidente en el arbitraje comercial privado, al menos no en todos los casos. No obstante que, en principio, puede ser cierto que los acuerdos arbitrales tienen un impacto directo en los riesgos y retornos de los inversores, la capacidad de arbitrar disputas parece no ser un factor tan crítico en un contrato entre partes comerciales como lo sería en una situación de tratado de inversión.

\section{4. ¿Un arbitraje bajo el Convenio CIADI sería diferente?}

Debido a que el caso $B G$ Group involucró la revisión de un laudo emitido en un arbitraje bajo las reglas de la CNUDMI por las cortes estadounidenses, un observador del arbitraje de inversión podría legítimamente preguntarse si la resolución del caso sería considerablemente distinta si el caso se hubiese regido por las Reglas de Arbitraje CIADI. CIADI es la institución más utilizada para los arbitrajes internacionales de inversión, y existen, de hecho, varias diferencias importantes entre los laudos CIADI y otros laudos arbitrales. Creemos que estas diferencias no habrían afectado la solución del caso BG Group porque, por las razones expuestas anteriormente, se debe otorgar deferencia a la interpretación de los árbitros de una cláusula que requiera litigación previa en un foro adjudicativo, aunque no vinculante, por un período de tiempo determinado. No obstante, a pesar de que el órgano revisor en un caso CIADI no habría llegado a una solución distinta que una Corte americana bajo este escenario fáctico, las diferencias en cuanto a la estructura y el estándar de revisión podrían marcar la diferencia en otros casos de "Zona Gris". 
Una vez que un laudo ha sido emitido, la estructura de revisión del laudo varía considerablemente bajo las Reglas del CIADI y bajo otras reglas arbitrales. En un arbitraje CIADI, una parte puede intentar anular un laudo arbitral sólo bajo las causales establecidas en el artículo 52 de la Convención de Washington ${ }^{23}$. Un comité ad hoc luego emite su decisión final sobre la anulación y, si la anulación no es concedida, el laudo es considerado vinculante para las partes conforme a los artículos 53 y 54 de la Convención de Washington ${ }^{24}$. Para un arbitraje bajo las reglas CNUDMI, por otro lado, la parte vencida puede intentar anular el laudo ante las cortes de la sede del arbitraje, con la posibilidad de múltiples apelaciones hasta la Corte Suprema local. Los casos "Zona Gris" pueden, en consecuencia, otorgar a diversas cortes nacionales (a diferentes niveles) la discreción de anular un laudo aplicando un estándar de revisión de novo. Si BG Group hubiese sido administrado por el CIADI, el proceso para impugnar el laudo arbitral habría sido más directo, y la parte vencida sólo hubiese tenido una oportunidad para intentar anular el laudo ante al comité de anulación.

Además, los laudos CIADI son ejecutados bajo la Convención de Washington, que obliga a los Estados parte a ejecutar las "obligaciones pecuniarias" impuestas por el laudo como si éstas fueran una decisión definitiva dictada por las cortes nacionales. La Convención de Washington restringe considerablemente la posibilidad de cuestionar la ejecución de un laudo CIADI ante las cortes nacionales ${ }^{25}$, aunque algunos comentaristas (y países) han sugerido que dichos laudos no estan totalmente blindados ${ }^{26}$. No obstante ello, ningún laudo CIADI ha visto su ejecución cuestionada exitosamente

23. Convención de Washington, infra 11, Art. 52(1).

24. Ibídem, Arts. 53(1), 54(1).

25. El artículo 53 establece que los laudos "son vinculantes" y "no podrán ser sometidos a apelación o a cualquier otro recurso" excepto por aquellos establecidos en la Convención. Ver, Maritime International Nominees Establishment (MINE) c. Republic of Guinea, Caso CIADI No. ARB/84/4, Decisión del Comité Ad Hoc del 14 de diciembre de 1989, disponible aquí: https://icsid.worldbank.org/ICSID/FrontServlet?requestType=CasesRH\&actionVal=showDoc\&docId=DC674_En\&caseId=C136 (el Convenio CIADI excluye cualquier impugnación del laudo ante las cortes nacionales).

26. Entre las posibilidades, creativas, para cuestionar la ejecución de laudos CIADI se encuentra la aplicación de la normativa local para reabrir decisiones finales, como ocurre con la regla 60(b) de las Federal Rules of Civil Procedure en los Estados Unidos; y la revisión judicial basada en los conceptos de orden público y derecho constitucional local. Véase, BALDWIN, KANTOR y NOLAN, "Limits to Enforcement of ICSID Awards", 23(1) Journal of International Arbitration 1 (2006), p. 6-10. Argentina ha expresamente argumentado, basándose en su Constitución, que los laudos CIADI deben guardar conformidad con sus principios de derecho público local y están sujetos a revisión judicial por sus Cortes locales. Véase, C. E. ALFARO y P. LORENTI, "Argentina vs. ICSID: Unconstitutionality of the BITs and ICSID Jurisdiction - the Potential New Government Defenses Against the Enforcement of the ICSID Arbitral Award", Mondaq (17 de mayo de 2005), disponible aquí: http://goo.gl/ RdN3w4. 
bajo ninguna de las causales sugeridas y, en cualquier caso, la Convención de Washington no contempla ninguna causal para impugnar la ejecución de un laudo. Por el contrario, laudos no-CIADI, incluyendo aquellos dictados bajo las reglas CNUDMI, son normalmente ejecutados bajo la Convención de Nueva York, la cual contempla causales claras en base a las cuales la ejecución de un laudo puede ser negada, incluyendo dos causales jurisdiccionales ${ }^{27}$. En consecuencia, laudos no-CIADI enfrentan la posibilidad de múltiples impugnaciones ante múltiples cortes nacionales con la discreción de revisar las determinaciones de los tribunales arbitrales sobre asuntos de competencia.

Adicionalmente, en casos difíciles de "Zona Gris" donde la línea entre jurisdicción y admisibilidad es menos clara, que una decisión sea dictada por un Comité Ad Hoc CIADI y no por jueces puede marcar la diferencia. Como las estadísticas del CIADI demuestran, sólo 1 de 18 solicitudes basadas en cuestionamientos de exceso de competencia resultó en la anulación total del laudo ${ }^{28}$. Por otro lado, en arbitrajes no sometidos a CIADI, las impugnaciones del laudo están sujetas a las particularidades de las leyes locales de la sede y a la idiosincrasia de los jueces nacionales, quienes pueden considerar, por ejemplo, sus políticas públicas locales. Sin embargo, esta diferencia posiblemente sea menos relevante en jurisdicciones pro-arbitraje, especialmente considerando las recientes tendencias para la armonización de las leyes arbitrales. En el caso BG Group, por ejemplo, las herramientas analíticas derivadas de la jurisprudencia de la Corte Suprema americana le permitirían alcanzar un resultado no diferente de aquél al que llegaría un Comité Ad Hoc de Anulación CIADI.

Lo que termina haciendo que CIADI sea un foro mas final y definitivo para el arbitraje es su estándar de revisión. Respecto de cuestionamientos de competencia, el artículo 52 de la Convención de Washington requiere prueba de un "manifiesto exceso de poder" a fin de anular un laudo ${ }^{29}$. Por el contrario, la Ley Federal de Arbitraje de los Estados Unidos sólo requiere prueba de que los árbitros "excedieron sus poderes" a fin de anular un lau$\mathrm{do}^{30}$. A primera impresión, es menos complicado anular un laudo bajo las

27. Convención sobre el Reconocimiento y la Ejecución de las Sentencias Arbitrales Extranjeras dictada el 10 de junio de1958, Articulos V(1)(a) y V(1)(c).

28. U.S. Federal Arbitration Act, 9 U.S Code 10 (a) (4) (2000).

29. Convención de Washington, infra nota 11, Art. 52(1)(b).

30. U.S. Federal Arbitration Act, 9 U.S. Code 10 (a) (4) (2000). 
reglas de CNUDMI ante las cortes americanas que bajo las reglas del CIADI, no obstante lo cual algunas recientes decisiones de anulación CIADI han tornado borrosa la línea entre la revisión limitada de competencia contemplada en la Convención de Washington y la revisión judicial total para los "errores de derecho", creando dudas acerca de cuál es el estándar de revisión adecuado en el procedimiento de anulación ${ }^{31}$. Queda pendiente ver, sin embargo, cómo otros comités de anulación responderán a estas recientes decisiones, que han sido objeto de muchas críticas. Finalmente, en un caso "Zona Gris" como el presente, la carga de probar que cualquier falta de competencia de los árbitros deba ser "manifiesta" haría que los cuestionamientos post-laudo basados en defectos de consentimiento tengan más dificultades para prosperar. Estos casos difíciles subrayan la importancia que tiene elegir la institución que administrará el procedimiento.

31. Sempra Energy International c. Argentine Republic, Caso CIADI No. ARB/02/16; Enron Creditos REcovery Cor. \& Ponderosa Assets, L.P. v. Argentine Republic, Caso CIADI No. ARB/01/3. 